\title{
10. ROCK MAGNETIC PROPERTIES OF SEDIMENTS FROM CEARA RISE (SITE 929): IMPLICATIONS FOR THE ORIGIN OF THE MAGNETIC SUSCEPTIBILITY SIGNAL ${ }^{1}$
}

\author{
Carl Richter, ${ }^{2}$ Jean-Pierre Valet, ${ }^{3}$ and Peter A. Solheid ${ }^{4}$
}

\begin{abstract}
This paper presents a rock magnetic study of cyclic deep-ocean sediment from the Ceara Rise in the equatorial Atlantic Ocean off the coast of Brazil. Whole-core magnetic susceptibility data have been used as a proxy for climate change in these sediments. This study is aimed at testing this assumption and at determining the source of the magnetic susceptibility variations. We analyzed hysteresis properties, high-field and low-field susceptibilities, anhysteretic remanent magnetization, and thermomagnetic behavior of 114 sediment samples. Hysteresis measurements show that the magnetic carrier is of pseudosingle domain size. Low-temperature demagnetization data indicate the Verwey transition (diagnostic of magnetite) at $118 \mathrm{~K}$. The magnetite concentration was estimated from the saturation magnetization values and varies between $43 \mathrm{ppm}$ in light, carbonaterich layers and $94 \mathrm{ppm}$ in dark, carbonate-poor layers. The average low-field mass susceptibility is $12.56 \times 10^{-8} \mathrm{~m}^{3} / \mathrm{kg}$, and the average high-field susceptibility is $4.8 \times 10^{-8} \mathrm{~m}^{3} / \mathrm{kg}$. The contribution of magnetite to the low-field susceptibility is $63 \%$ in carbonate-poor layers and $53 \%$ in carbonate-rich layers. Concentration-independent rock magnetic ratios revealed small-scale and large-scale variations in the magnetic grain size. The variations in magnetic properties mirror changes in clay content, which provides excellent evidence that the susceptibility variations reflect fluctuations in sedimentary input from the Amazon River. The dominant control on Amazon-derived terrigenous sediment is sea level. Therefore, it appears that magnetic susceptibility is a valid climate proxy for the Ceara Rise sediments.
\end{abstract}

\section{INTRODUCTION}

Ocean Drilling Program (ODP) Leg 154 drilled Site 929 on the northern flank of the Ceara Rise (Fig. 1) in the equatorial Atlantic Ocean $\left(5^{\circ} 58.566^{\prime} \mathrm{N}, 43^{\circ} 44.394^{\prime} \mathrm{W}\right)$. The site is the deepest of the depth transects of sites on the Ceara Rise (Curry, Shackleton, Richter, et al., 1995). The seafloor is at a depth of $4356 \mathrm{~m}$ below the present lysocline, but is close to the carbonate compensation depth (CCD). Hole 929C penetrated $155 \mathrm{~m}$ of clays and nannofossil clays, ranging in age from Pleistocene to early Miocene. Hole 929D recovered $54 \mathrm{~m}$ of Pleistocene clays and nannofossil clays. Nearly the entire sequence is characterized by rhythmic sedimentary cycles that are chiefly related to the 41-k.y. orbital obliquity cycles; however, the late Pleistocene is more influenced by the eccentricity cycle (Bickert et al., Chapter 16, this volume; Curry, Shackleton, Richter, et al., 1995). These sedimentary cycles are well-recorded by magnetic susceptibility, color, and natural gamma-ray emission. High-resolution magnetic susceptibility measurements of whole-core sections from Holes 929A through 929E displayed peaks with amplitudes of $15.4 \times$ $10^{-6}$ to $1085.7 \times 10^{-6} \mathrm{SI}$ and periods of tens of centimeters. The magnetic susceptibility data are negatively correlated to calcium carbonate percentage (Curry, Shackleton, Richter, et al., 1995; Shipboard Scientific Party, 1995) and have been used as indicators of changing sedimentary conditions. Variations in grain size, mineralogy, and concentration of magnetic grains reflect pre- and post-depositional environmental changes, and can yield clues to fluctuations in climate and the depositional environment.

Magnetic susceptibility records of loess deposits in China have been examined for clues concerning their relationship to climate-

${ }^{1}$ Shackleton, N.J., Curry, W.B., Richter, C., and Bralower, T.J. (Eds.), 1997. Proc. ODP, Sci. Results, 154: College Station, TX (Ocean Drilling Program).

${ }^{2}$ Ocean Drilling Program, Texas A\&M University, College Station, TX 77845, U.S.A. Richter@tamu.edu

${ }^{3}$ Institut de Physique du Globe, 4 Place Jussieu, 75252 Paris Cedex 05, France.

${ }^{4}$ Institute for Rock Magnetism, University of Minnesota, Minneapolis, MN 55455, U.S.A. forcing orbital frequencies (e.g., Kukla et al., 1988; Kukla and An, 1989). Magnetic susceptibility has also been compared to commonly used paleoclimate indicators, such as calcium carbonate percentages and oxygen isotopes in deep-sea sediments (e.g., Kent, 1982; Mead et al., 1986; Robinson, 1986; Bloemendal et al., 1988; Bloemendal and deMenocal, 1989; Verosub and Roberts, 1995). Recent trends in paleoclimate studies using magnetic susceptibility are to attempt correlation of susceptibility records across an ocean basin (Bloemendal et al., 1992) or to link continental and marine sediment sections by comparing magnetic susceptibility and oxygen isotope records - for example, correlation of loess sequences in China with age-equivalent marine sediments in the western Pacific Ocean (Kukla et al., 1988; Hovan et al., 1989; Maher and Thompson, 1992).

Magnetic susceptibility data appear to vary on orbital time scales and are a cornerstone of the Leg 154 results. Numerous studies have used the magnetic susceptibility record as a climate data proxy. Complete stratigraphic recovery was crucial to fulfill the paleoceanographic objectives of the cruise and was achieved with an intercore correlation technique (Hagelberg et al., 1992), which is based on high-resolution magnetic susceptibility, color, and natural gammaray emission data. Preliminary shipboard analysis used magnetic susceptibility as a carbonate proxy $\left(\mathrm{R}^{2}=0.52\right.$ for carbonate-susceptibility correlation) to obtain high-resolution data from low-resolution carbonate measurements for paleoceanographic interpretation (Shipboard Scientific Party, 1995). For these reasons, it is extremely important to document the factors resulting in the susceptibility variations. In this study, we investigate the source of the magnetic susceptibility variations by characterizing various rock magnetic properties. This step is necessary to make a convincing case for the separation of regional and global signals and to correlate on a global scale.

\section{SAMPLING AND EXPERIMENTAL PROCEDURES}

Volume magnetic susceptibility of sediments from Site 929 was measured every $10 \mathrm{~cm}$ aboard the JOIDES Resolution on whole-core sections using a Bartington Instruments MS-2 susceptibility meter. 
Figure 1. Generalized location map of Site 929 on the northern flank of the Ceara Rise in the equatorial Atlantic (inset). Bathymetry in meters. After Mountain and Curry (1995).

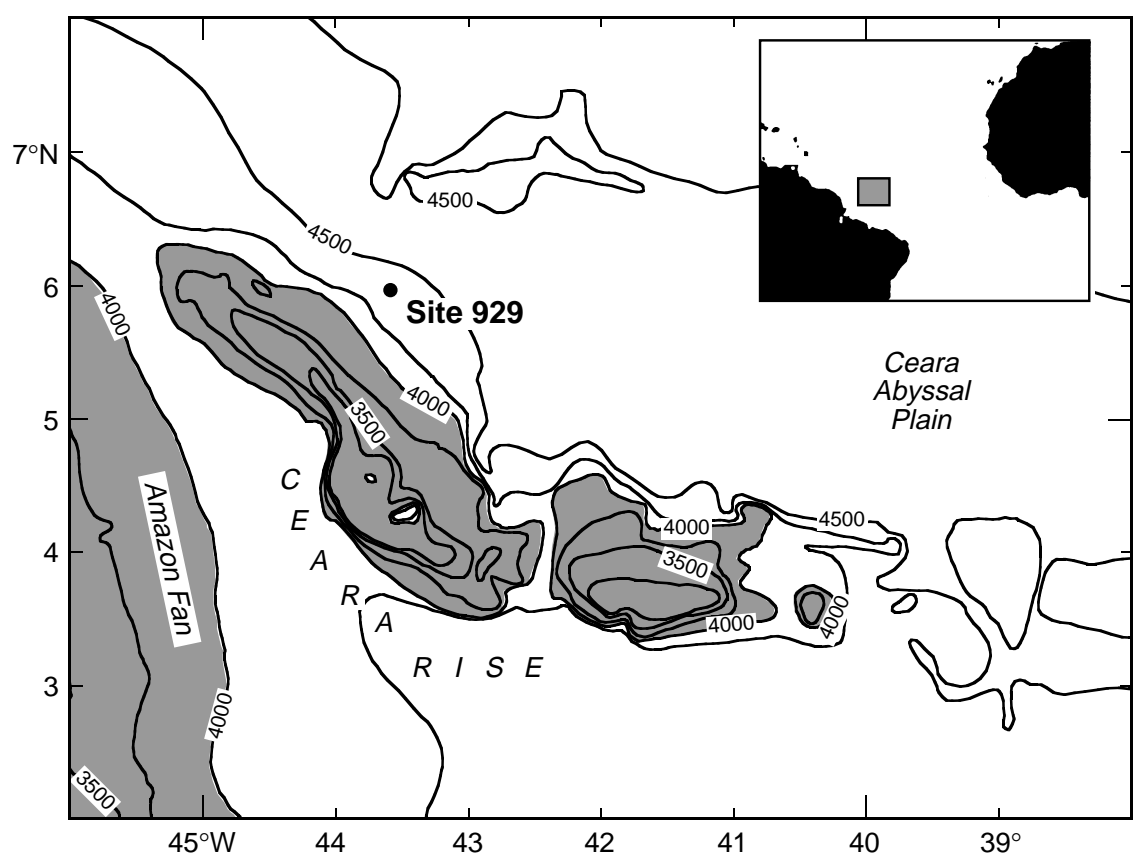

$300 \mathrm{~K}$ in a zero field. The low-field magnetic susceptibility was measured as a function of temperature using a LakeShore Cryotronics Model 7130 AC susceptometer between 20 and $300 \mathrm{~K}$ and the CS-2 furnace attachment for the Kappabridge between 300 and $970 \mathrm{~K}$. field of $0.1 \mathrm{mT}$ at a frequency of $470 \mathrm{~Hz}$. The raw instrument units were converted into volume SI units by a single multiplication with a calibration factor $\left(7.7 \times 10^{-6}\right)$.

Detailed rock magnetic characterization was undertaken on 114 samples $\left(6 \mathrm{~cm}^{3}\right)$ that were taken from Cores 154-929D-1H through $6 \mathrm{H}$ and $154-929 \mathrm{C}-7 \mathrm{H}$ through $9 \mathrm{H}$ between depths of 3.50 and 84.25 meters below seafloor (mbsf; Table 1) at a frequency of 2-6 samples per $1.5-\mathrm{m}$ section of core (every $75-25 \mathrm{~cm}$ ). The samples were selected from dark- $(\mathrm{N}=51)$, light- $(\mathrm{N}=39)$, and intermediate- $(\mathrm{N}=24)$ colored intervals and represent the end members and the transitions of the cyclic calcium carbonate variations observed in these cores. To facilitate the comparison between samples from different holes and between different studies, we express depth not only on the standard ODP mbsf scale (Table 1), but also on the meters composite depth (mcd) scale, which was established by intercore correlation procedures during Leg 154 (Curry, Shackleton, Richter, et al., 1995).

The low-field mass susceptibility of the samples was measured using a KLY-2 Kappabridge magnetic susceptibility meter (Geofyzika Brno, inducing field $=0.5 \mathrm{mT}$ ) at the Institute for Rock Magnetism (IRM) at the University of Minnesota. High-field susceptibilities (up to $1.5 \mathrm{~T}$ ) and hysteresis properties were determined on the $6 \mathrm{~cm}^{3}$ samples using the in-house built vibrating sample magnetometer (VSM) at the IRM. An anhysteretic remanent magnetization (ARM) was imparted to each sample by exposing it to both a constant 0.05 $\mathrm{mT}$ field and a slowly decaying $100 \mathrm{mT}$ alternating field (AF). Partial anhysteretic remanence magnetizations (pARM) were imparted by switching on a DC bias field between two specified values of the applied AF. Grains with coercivity of remanence $\left(H_{c r}\right)$ between the two fields will acquire an ARM, whereas the rest of the assemblage is demagnetized. By moving the window over a range of alternating fields, a pARM curve is obtained which represents the spectrum of coercivities in the sample (Jackson et al., 1988, 1989). The acquired ARM and pARM were measured using the $2 \mathrm{G}$ three-axis Superconducting Rock Magnetometer at the IRM. Low-temperature demagnetization of the saturation isothermal remanent magnetization (SIRM) was conducted using a Quantum Design Magnetic Property Measurement System (MPMS). A $2.5 \mathrm{~T}$ field was imparted at $20 \mathrm{~K}$ and the magnetic moment was recorded in $5 \mathrm{~K}$ steps while heating from 20 to

\section{RESULTS}

\section{Low-Field Susceptibility}

Whole-core and discrete susceptibility measurements show both large-scale variations with a wavelength of tens of meters and smaller wavelength fluctuations of about $50 \mathrm{~cm}$ or less (Fig. 2). Whole-core susceptibility values vary from $15.4 \times 10^{-6}$ to $1085.7 \times 10^{-6}$ vol SI (average $=205.6 \times 10^{-6}$ ) and discrete measurements range from 5.34 $\times 10^{-8} \mathrm{~m}^{3} / \mathrm{kg}$ to $31.72 \times 10^{-8} \mathrm{~m}^{3} / \mathrm{kg}$ (average $=12.56 \times 10^{-8} \mathrm{~m}^{3} / \mathrm{kg}$ ). The mass and volume susceptibilities cannot be accurately converted into the same units because the density of the whole-core data and the exact volume of the discrete samples is unknown. However, a comparison between whole core and discrete sample data shows an extremely good correlation $\left(\mathrm{R}^{2}=0.91\right)$. Differences between the measurements are caused mainly by the fact that discrete specimens represent mass susceptibilities of a well-defined small area, whereas the whole-core measurements represent volume susceptibilities within a 15 -cm-wide response curve and an assumed volume that depends on how well the core liner is filled.

The average low-field mass susceptibility of the dark, carbonate-poor layers is $15.5 \times 10^{-8} \mathrm{~m}^{3} / \mathrm{kg}$; the transitional layers is $12.1 \times$ $10^{-8} \mathrm{~m}^{3} / \mathrm{kg}$; and the light, carbonate-rich layers is $8.7 \times 10^{-8} \mathrm{~m}^{3} / \mathrm{kg}$ (Table 2). Shipboard analysis indicates (Curry, Shackleton, Richter, et al., 1995) that magnetic susceptibility is negatively correlated to the concentration of calcium carbonate, which varies between $0.5 \%$ and $50 \%$ in the investigated section at Site 929 . The magnitude of susceptibility is a function of the dilution of a paramagnetic and ferrimagnetic (terrigenous) phase with diamagnetic calcium carbonate $\left(-12.4\right.$ to $\left.-13.8 \times 10^{-6} \mathrm{vol} \mathrm{SI}\right)$, and the composition of the paramagnetic and ferrimagnetic phases.

The low-field susceptibility $\left(k_{l f}\right)$ represents the induced magnetization of all minerals (diamagnetic, paramagnetic, antiferromagnetic, and ferrimagnetic) in the rock under investigation. 
Table 1. Rock magnetic parameters.

\begin{tabular}{|c|c|c|c|c|c|c|c|c|}
\hline $\begin{array}{l}\text { Core, section, } \\
\text { interval }(\mathrm{cm})\end{array}$ & $\begin{array}{l}\text { Depth } \\
\text { (mbsf) }\end{array}$ & $\begin{array}{l}\text { Depth } \\
\text { (mcd) }\end{array}$ & $\begin{array}{c}k_{h f} \\
\left(\mathrm{~m}^{3} / \mathrm{kg} \times 10^{-8}\right)\end{array}$ & $\begin{array}{c}k_{l f} \\
\left(\mathrm{~m}^{3} / \mathrm{kg} \times 10^{-8}\right)\end{array}$ & $\begin{array}{c}M_{s} \\
\left(\mathrm{Am}^{2} / \mathrm{kg}\right)\end{array}$ & $\begin{array}{c}M_{r s} \\
\left(\mathrm{Am}^{2} / \mathrm{kg}\right)\end{array}$ & $\begin{array}{c}H_{c} \\
(\mathrm{mT})\end{array}$ & $\begin{array}{c}H_{c r} \\
(\mathrm{mT})\end{array}$ \\
\hline 154-929D- & & & & & & & & \\
\hline $1 \mathrm{H}-3,0.50$ & 3.50 & 3.91 & 4.20 & 18.94 & 0.011800 & 0.001890 & 10.99 & 32.42 \\
\hline $1 \mathrm{H}-3,0.65$ & 3.65 & 4.06 & 3.50 & 12.93 & 0.007510 & 0.001400 & 12.28 & 33.77 \\
\hline $1 \mathrm{H}-3,0.90$ & 3.90 & 4.31 & 3.19 & 8.45 & 0.004730 & 0.000977 & 13.00 & 35.47 \\
\hline $1 \mathrm{H}-3,1.05$ & 4.05 & 4.46 & 4.50 & 31.72 & 0.023700 & 0.002420 & 7.76 & 28.14 \\
\hline $1 \mathrm{H}-3,1.20$ & 4.20 & 4.61 & 4.16 & 12.16 & 0.006160 & 0.001220 & 12.54 & 35.11 \\
\hline $1 \mathrm{H}-4,0.25$ & 4.75 & 5.16 & 3.04 & 7.47 & 0.003330 & 0.000783 & 13.51 & 32.88 \\
\hline $1 \mathrm{H}-4,0.55$ & 5.05 & 5.46 & 4.36 & 9.69 & 0.004670 & 0.001010 & 13.62 & 34.93 \\
\hline $1 \mathrm{H}-4,0.90$ & 5.40 & 5.81 & 3.37 & 5.70 & 0.002630 & 0.000551 & 13.56 & 38.96 \\
\hline $2 \mathrm{H}-2,0.65$ & 9.15 & 9.81 & 5.73 & 18.84 & 0.013600 & 0.002490 & 14.72 & 47.20 \\
\hline $2 \mathrm{H}-2,1.00$ & 9.50 & 10.16 & 3.12 & 6.63 & 0.003540 & 0.000811 & 14.84 & 37.28 \\
\hline $2 \mathrm{H}-2,1.35$ & 9.85 & 10.51 & 3.74 & 10.19 & 0.004690 & 0.001080 & 13.36 & 35.28 \\
\hline $2 \mathrm{H}-3,0.15$ & 10.15 & 10.81 & 4.76 & 10.45 & 0.006270 & 0.001250 & 13.43 & 36.97 \\
\hline $2 \mathrm{H}-3,0.60$ & 10.60 & 11.26 & 2.23 & 5.40 & 0.002870 & 0.000726 & 15.79 & 37.67 \\
\hline $2 \mathrm{H}-3,0.80$ & 10.80 & 11.46 & 3.76 & 9.63 & 0.004090 & 0.001160 & 16.17 & 42.41 \\
\hline $2 \mathrm{H}-3,1.30$ & 11.30 & 11.96 & 3.35 & 8.88 & 0.004480 & 0.001120 & 14.78 & 38.88 \\
\hline $2 \mathrm{H}-4,0.35$ & 11.85 & 12.51 & 5.31 & 18.02 & 0.012200 & 0.002350 & 14.77 & 43.52 \\
\hline $2 \mathrm{H}-4,0.65$ & 12.15 & 12.81 & 4.99 & 14.35 & 0.007290 & 0.001500 & 13.46 & 39.50 \\
\hline $2 \mathrm{H}-4,0.90$ & 12.40 & 13.06 & 6.16 & 15.75 & 0.009650 & 0.002990 & 22.02 & 58.43 \\
\hline $2 \mathrm{H}-4,1.20$ & 12.70 & 13.36 & 4.11 & 9.16 & 0.003920 & 0.000941 & 15.03 & 40.61 \\
\hline $2 \mathrm{H}-4,1.45$ & 12.95 & 13.61 & 6.28 & 13.93 & 0.005860 & 0.001460 & 15.20 & 40.59 \\
\hline $2 \mathrm{H}-5,0.20$ & 13.20 & 13.86 & 4.69 & 12.35 & 0.006010 & 0.001380 & 14.35 & 39.61 \\
\hline $2 \mathrm{H}-5,0.40$ & 13.40 & 14.06 & 4.78 & 11.34 & 0.005380 & 0.001330 & 14.66 & 37.36 \\
\hline $2 \mathrm{H}-5,0.55$ & 13.55 & 14.21 & 5.49 & 14.13 & 0.007730 & 0.002970 & 29.71 & 71.96 \\
\hline $2 \mathrm{H}-5,0.80$ & 13.80 & 14.46 & 3.36 & 6.31 & 0.002930 & 0.000663 & 14.09 & 36.96 \\
\hline $2 \mathrm{H}-5,1.20$ & 14.20 & 14.86 & 3.10 & 5.70 & 0.002020 & 0.000607 & 14.35 & 33.01 \\
\hline $2 \mathrm{H}-6,0.30$ & 14.80 & 15.46 & 4.23 & 10.47 & 0.004970 & 0.001130 & 14.00 & 36.51 \\
\hline $2 \mathrm{H}-6,0.65$ & 15.15 & 15.81 & 4.81 & 13.16 & 0.006030 & 0.001370 & 13.70 & 37.67 \\
\hline $2 \mathrm{H}-6,1.25$ & 15.75 & 16.41 & 4.58 & 12.69 & 0.006370 & 0.001310 & 13.57 & 37.86 \\
\hline $3 \mathrm{H}-1,0.50$ & 17.00 & 18.93 & 5.03 & 11.80 & 0.005950 & 0.001800 & 13.32 & 50.59 \\
\hline $3 \mathrm{H}-1,1.00$ & 17.50 & 19.43 & 5.02 & 10.51 & 0.004890 & 0.001580 & 20.02 & 51.15 \\
\hline $3 \mathrm{H}-1,1.35$ & 17.85 & 19.78 & 5.07 & 12.63 & 0.011400 & 0.006390 & 49.74 & 75.37 \\
\hline $3 \mathrm{H}-2,0.30$ & 18.30 & 20.23 & 4.13 & 8.69 & 0.003630 & 0.001150 & 19.04 & 48.73 \\
\hline $3 \mathrm{H}-2,0.45$ & 18.45 & 20.38 & 3.91 & 9.21 & 0.004140 & 0.001220 & 17.57 & 43.65 \\
\hline $3 \mathrm{H}-2,0.70$ & 18.70 & 20.63 & 4.29 & 9.85 & 0.004360 & 0.001070 & 14.23 & 35.25 \\
\hline $3 \mathrm{H}-2,1.10$ & 19.10 & 21.03 & 5.58 & 22.62 & 0.014200 & 0.001850 & 9.41 & 31.17 \\
\hline $3 \mathrm{H}-2,1.40$ & 19.40 & 21.33 & 4.64 & 14.16 & 0.008600 & 0.001520 & 12.62 & 35.32 \\
\hline $3 \mathrm{H}-3,0.30$ & 19.80 & 21.73 & 4.13 & 9.00 & 0.004360 & 0.001050 & 15.05 & 39.52 \\
\hline $3 \mathrm{H}-3,0.60$ & 20.10 & 22.03 & 6.72 & 14.99 & 0.006600 & 0.002010 & 19.33 & 49.01 \\
\hline $3 \mathrm{H}-3,0.80$ & 20.30 & 22.23 & 4.36 & 11.85 & 0.006250 & 0.001310 & 14.41 & 38.56 \\
\hline $3 \mathrm{H}-3,1.40$ & 20.90 & 22.83 & 5.63 & 19.80 & 0.013200 & 0.002340 & 13.20 & 38.79 \\
\hline $3 \mathrm{H}-4,0.10$ & 21.10 & 23.03 & 5.21 & 14.22 & 0.007820 & 0.002210 & 18.83 & 51.22 \\
\hline $3 \mathrm{H}-4,0.30$ & 21.30 & 23.23 & 5.09 & 10.67 & 0.005320 & 0.001560 & 18.55 & 48.04 \\
\hline $3 \mathrm{H}-4,0.70$ & 21.70 & 23.63 & 4.42 & 8.38 & 0.003430 & 0.000885 & 14.18 & 34.76 \\
\hline $3 \mathrm{H}-4,0.85$ & 21.85 & 23.78 & 6.07 & 16.14 & 0.007980 & 0.002190 & 17.84 & 50.21 \\
\hline $3 \mathrm{H}-4,1.10$ & 22.10 & 24.03 & 6.75 & 21.54 & 0.012600 & 0.002600 & 14.02 & 41.64 \\
\hline $3 \mathrm{H}-4,1.35$ & 22.35 & 24.28 & 4.10 & 12.73 & 0.007650 & 0.001660 & 15.45 & 43.06 \\
\hline $3 \mathrm{H}-5,0.10$ & 22.60 & 24.53 & 4.70 & 12.59 & 0.006000 & 0.001490 & 15.08 & 38.70 \\
\hline $3 \mathrm{H}-5,0.30$ & 22.80 & 24.73 & 4.17 & 10.83 & 0.005440 & 0.001500 & 17.71 & 46.30 \\
\hline $3 \mathrm{H}-5,0.55$ & 23.05 & 24.98 & 3.94 & 8.75 & 0.003470 & 0.000866 & 13.93 & 35.38 \\
\hline $3 \mathrm{H}-5,0.75$ & 23.25 & 25.18 & 5.92 & 16.47 & 0.007360 & 0.001650 & 13.10 & 36.06 \\
\hline $3 \mathrm{H}-5,1.10$ & 23.60 & 25.53 & 5.09 & 16.91 & 0.009510 & 0.001860 & 12.64 & 34.86 \\
\hline $3 \mathrm{H}-5,1.40$ & 23.90 & 25.83 & 5.63 & 21.81 & 0.013500 & 0.002410 & 10.49 & 37.73 \\
\hline $3 \mathrm{H}-6,0.25$ & 24.25 & 26.18 & 4.90 & 15.88 & 0.014000 & 0.006500 & 42.65 & 74.70 \\
\hline $3 \mathrm{H}-6,0.55$ & 24.55 & 26.48 & 5.60 & 18.30 & 0.015500 & 0.006600 & 38.70 & 74.34 \\
\hline $3 \mathrm{H}-6,0.95$ & 24.95 & 26.88 & 5.59 & 19.70 & 0.011900 & 0.003060 & 17.99 & 53.16 \\
\hline $4 \mathrm{H}-1,0.50$ & 26.50 & 28.76 & 4.57 & 13.84 & 0.007010 & 0.001460 & 13.35 & 35.69 \\
\hline $4 \mathrm{H}-1,1.20$ & 27.20 & 29.46 & 4.48 & 12.87 & 0.006570 & 0.001590 & 16.08 & 43.07 \\
\hline $4 \mathrm{H}-2,0.25$ & 27.75 & 30.01 & 5.44 & 18.68 & 0.011000 & 0.002700 & 16.71 & 45.40 \\
\hline $4 \mathrm{H}-2,1.05$ & 28.55 & 30.81 & 5.99 & 12.05 & 0.004770 & 0.001090 & 13.44 & 34.32 \\
\hline $4 \mathrm{H}-2,1.25$ & 28.75 & 31.01 & 4.47 & 24.15 & 0.018100 & 0.002640 & 12.08 & 37.70 \\
\hline $4 \mathrm{H}-3,0.20$ & 29.20 & 31.46 & 5.73 & 27.07 & 0.016000 & 0.002660 & 11.47 & 32.95 \\
\hline $4 \mathrm{H}-3,0.85$ & 29.85 & 32.11 & 4.12 & 12.64 & 0.007210 & 0.001530 & 13.90 & 36.36 \\
\hline $4 \mathrm{H}-3,1.30$ & 30.30 & 32.56 & 5.49 & 19.48 & 0.010100 & 0.002360 & 14.58 & 38.95 \\
\hline $4 \mathrm{H}-4,0.15$ & 30.65 & 32.91 & 5.14 & 14.68 & 0.006110 & 0.001510 & 13.12 & 33.59 \\
\hline $4 \mathrm{H}-4,0.35$ & 30.85 & 33.11 & 4.40 & 10.03 & 0.004310 & 0.001110 & 13.95 & 33.41 \\
\hline $4 \mathrm{H}-4,1.10$ & 31.60 & 33.86 & 5.82 & 17.38 & 0.007970 & 0.001970 & 13.89 & 35.03 \\
\hline $4 \mathrm{H}-5,0.50$ & 32.50 & 34.76 & 6.26 & 18.96 & 0.008650 & 0.002060 & 13.63 & 35.82 \\
\hline $4 \mathrm{H}-5,1.40$ & 33.40 & 35.66 & 4.17 & 9.56 & 0.003820 & 0.000973 & 13.75 & 34.76 \\
\hline $4 \mathrm{H}-6,0.65$ & 34.15 & 36.41 & 4.52 & 11.78 & 0.005170 & 0.001250 & 13.46 & 33.43 \\
\hline $4 \mathrm{H}-6,1.00$ & 34.50 & 36.76 & 7.30 & 25.53 & 0.014700 & 0.002900 & 13.17 & 37.22 \\
\hline $4 \mathrm{H}-6,1.40$ & 34.90 & 37.16 & 3.55 & 9.32 & 0.004950 & 0.001110 & 13.76 & 34.18 \\
\hline $5 \mathrm{H}-1,1.00$ & 36.50 & 39.72 & 6.63 & 18.88 & 0.010500 & 0.002160 & 14.01 & 41.12 \\
\hline $5 \mathrm{H}-2,0.10$ & 37.10 & 40.32 & 4.51 & 9.38 & 0.003750 & 0.000877 & 13.71 & 35.42 \\
\hline $5 \mathrm{H}-2,0.40$ & 37.40 & 40.62 & 5.89 & 16.58 & 0.007060 & 0.001650 & 12.99 & 35.12 \\
\hline $5 \mathrm{H}-2,1.15$ & 38.15 & 41.37 & 4.43 & 9.49 & 0.003990 & 0.001050 & 13.98 & 33.32 \\
\hline $5 \mathrm{H}-3,0.70$ & 39.20 & 42.42 & 4.19 & 9.33 & 0.004100 & 0.000970 & 13.50 & 34.75 \\
\hline $5 \mathrm{H}-4,0.40$ & 40.40 & 43.62 & 6.72 & 19.91 & 0.010800 & 0.003460 & 21.21 & 56.23 \\
\hline $5 \mathrm{H}-4,0.85$ & 40.85 & 44.07 & 4.74 & 9.64 & 0.003810 & 0.001090 & 15.53 & 37.40 \\
\hline $5 \mathrm{H}-4,1.40$ & 41.40 & 44.62 & 5.92 & 19.20 & 0.007640 & 0.001930 & 13.90 & 38.73 \\
\hline $5 \mathrm{H}-5,0.25$ & 41.75 & 44.97 & 6.01 & 16.35 & 0.008170 & 0.002690 & 20.85 & 54.54 \\
\hline $5 \mathrm{H}-5,0.80$ & 42.30 & 45.52 & 3.63 & 7.37 & 0.002640 & 0.000786 & 15.51 & 37.05 \\
\hline $5 \mathrm{H}-5,1.05$ & 42.55 & 45.77 & 5.22 & 13.57 & 0.006350 & 0.002270 & 23.55 & 58.78 \\
\hline $5 \mathrm{H}-6,0.10$ & 43.10 & 46.32 & 5.84 & 14.83 & 0.005840 & 0.001690 & 15.63 & 40.26 \\
\hline $5 \mathrm{H}-6,0.40$ & 43.40 & 46.62 & 3.56 & 6.62 & 0.002340 & 0.000723 & 16.79 & 39.86 \\
\hline $5 \mathrm{H}-6,0.55$ & 43.55 & 46.77 & 4.47 & 8.16 & 0.003570 & 0.001230 & 21.61 & 54.63 \\
\hline $5 \mathrm{H}-6,1.20$ & 44.20 & 47.42 & 5.61 & 13.42 & 0.007010 & 0.003130 & 32.10 & 64.90 \\
\hline $6 \mathrm{H}-1,0.30$ & 45.30 & 49.49 & 4.25 & 8.02 & 0.002960 & 0.000826 & 15.76 & 40.92 \\
\hline $6 \mathrm{H}-1,0.75$ & 45.75 & 49.94 & 5.60 & 11.78 & 0.006870 & 0.002810 & 30.81 & 68.50 \\
\hline
\end{tabular}


Table 1 (continued).

\begin{tabular}{|c|c|c|c|c|c|c|c|c|c|c|}
\hline $\begin{array}{l}\text { Core, section, } \\
\text { interval }(\mathrm{cm})\end{array}$ & $\begin{array}{l}\text { Depth } \\
\text { (mbsf) }\end{array}$ & $\begin{array}{l}\text { Depth } \\
\text { (mcd) }\end{array}$ & $\begin{array}{c}k_{h f} \\
\left(\mathrm{~m}^{3} / \mathrm{kg} \times 10^{-8}\right)\end{array}$ & $\begin{array}{c}k_{l f} \\
\left(\mathrm{~m}^{3} / \mathrm{kg} \times 10^{-8}\right)\end{array}$ & $\begin{array}{c}M_{s} \\
\left(\mathrm{Am}^{2} / \mathrm{kg}\right)\end{array}$ & $\begin{array}{c}M_{r s} \\
\left(\mathrm{Am}^{2} / \mathrm{kg}\right)\end{array}$ & $\begin{array}{c}H_{c} \\
(\mathrm{mT})\end{array}$ & $\begin{array}{c}H_{c r} \\
(\mathrm{mT})\end{array}$ & $\begin{array}{l}\text { ARM } \\
(\mathrm{A} / \mathrm{m})\end{array}$ & $\begin{array}{c}\text { Magnetite } \\
(\%)\end{array}$ \\
\hline $6 \mathrm{H}-1,1.00$ & 46.00 & 50.19 & 4.82 & 8.69 & 0.003940 & 0.001850 & 33.76 & 70.19 & 0.22 & 0.0043 \\
\hline $6 \mathrm{H}-1,1.15$ & 46.15 & 50.34 & 5.62 & 10.34 & 0.004740 & 0.002010 & 29.17 & 65.08 & 0.16 & 0.0052 \\
\hline $6 \mathrm{H}-2,0.50$ & 47.00 & 51.19 & 3.40 & 5.34 & 0.001970 & 0.000629 & 16.82 & 37.08 & 0.19 & 0.0021 \\
\hline $6 \mathrm{H}-2,1.25$ & 47.75 & 51.94 & 7.49 & 23.06 & 0.017100 & 0.005480 & 21.10 & 70.39 & 0.20 & 0.0186 \\
\hline $6 \mathrm{H}-3,0.25$ & 48.25 & 52.44 & 3.63 & 5.83 & 0.002720 & 0.001000 & 22.76 & 54.43 & 0.12 & 0.0030 \\
\hline $6 \mathrm{H}-3,0.65$ & 48.65 & 52.84 & 4.55 & 9.63 & 0.004510 & 0.001390 & 18.82 & 49.97 & 0.19 & 0.0049 \\
\hline $6 \mathrm{H}-3,1.05$ & 49.05 & 53.24 & 4.86 & 10.81 & 0.005150 & 0.001330 & 15.33 & 42.05 & 0.18 & 0.0056 \\
\hline \multicolumn{11}{|l|}{$154-929 \mathrm{C}-$} \\
\hline $7 \mathrm{H}-1,0.20$ & 60.20 & 65.09 & 4.44 & 8.45 & 0.004010 & 0.001060 & 14.99 & 37.64 & 0.11 & 0.0044 \\
\hline $7 \mathrm{H}-1,0.50$ & 60.50 & 65.39 & 5.01 & 8.79 & 0.004260 & 0.001340 & 20.04 & 54.95 & 0.17 & 0.0046 \\
\hline $7 \mathrm{H}-1,0.75$ & 60.75 & 65.64 & 3.97 & 7.04 & 0.002530 & 0.000708 & 14.66 & 37.09 & 0.16 & 0.0028 \\
\hline $7 \mathrm{H}-1,1.00$ & 61.00 & 65.89 & 3.81 & 8.36 & 0.003340 & 0.000915 & 16.22 & 43.97 & 0.20 & 0.0036 \\
\hline $7 \mathrm{H}-1,1.15$ & 61.15 & 66.04 & 6.37 & 14.29 & 0.005730 & 0.001620 & 15.40 & 39.49 & 0.30 & 0.0062 \\
\hline $7 \mathrm{H}-1,1.30$ & 61.30 & 66.19 & 4.78 & 9.93 & 0.004510 & 0.001110 & 19.36 & 34.09 & 0.17 & 0.0049 \\
\hline $7 \mathrm{H}-2,0.20$ & 61.70 & 66.59 & 4.15 & 8.24 & 0.003300 & 0.000815 & 13.33 & 32.54 & 0.18 & 0.0036 \\
\hline $7 \mathrm{H}-2,0.40$ & 61.90 & 66.79 & 5.87 & 14.27 & 0.005800 & 0.001330 & 12.47 & 33.10 & 0.27 & 0.0063 \\
\hline $7 \mathrm{H}-2,0.80$ & 62.30 & 67.19 & 5.03 & 11.84 & 0.005360 & 0.001200 & 12.64 & 32.56 & 0.24 & 0.0058 \\
\hline $7 \mathrm{H}-2,1.20$ & 62.70 & 67.59 & 2.69 & 5.36 & 0.002490 & 0.000726 & 14.60 & 33.97 & 0.19 & 0.0027 \\
\hline $7 \mathrm{H}-3,0.55$ & 63.55 & 68.44 & 4.93 & 11.91 & 0.005100 & 0.001280 & 13.46 & 35.37 & 0.23 & 0.0055 \\
\hline $7 \mathrm{H}-4,0.55$ & 65.05 & 69.94 & 3.89 & 6.97 & 0.002980 & 0.000942 & 17.91 & 45.55 & 0.12 & 0.0032 \\
\hline $7 \mathrm{H}-4,1.00$ & 65.50 & 70.39 & 3.99 & 7.78 & 0.003030 & 0.000842 & 15.96 & 41.87 & 0.15 & 0.0033 \\
\hline $7 \mathrm{H}-5,0.65$ & 66.65 & 71.54 & 4.79 & 8.14 & 0.003450 & 0.001400 & 26.53 & 61.01 & 0.13 & 0.0038 \\
\hline $7 \mathrm{H}-6,0.80$ & 68.30 & 73.19 & 4.67 & 11.15 & 0.007460 & 0.003360 & 34.01 & 66.68 & 0.16 & 0.0081 \\
\hline $8 \mathrm{H}-3,0.75$ & 73.25 & 78.40 & 4.40 & 9.54 & 0.002760 & 0.000762 & 15.49 & 40.23 & 0.15 & 0.0030 \\
\hline $8 \mathrm{H}-6,0.80$ & 77.80 & 82.95 & 4.58 & 6.89 & 0.002560 & 0.000861 & 20.91 & 51.04 & 0.12 & 0.0028 \\
\hline $9 \mathrm{H}-2,0.80$ & 81.30 & 86.84 & 4.28 & 6.79 & 0.003790 & 0.001030 & 15.70 & 40.93 & 0.14 & 0.0041 \\
\hline $9 \mathrm{H}-4,0.75$ & 84.25 & 89.79 & 4.96 & 7.52 & 0.003410 & 0.000960 & 16.76 & 41.43 & 0.07 & 0.0037 \\
\hline
\end{tabular}

Specifically,

$$
k_{l f}=k_{\text {para }}+k_{\text {dia }}+k_{\text {antiferro }}+k_{\text {ferri }},
$$

where $k_{\text {para }}, k_{\text {dia }}, k_{\text {antiferro }}$, and $k_{\text {ferri }}$ are the contributions of the paramagnetic, diamagnetic, antiferromagnetic, and ferrimagnetic susceptibilities, respectively. The high-field susceptibility, $k_{h f}$, at fields above the saturation magnetization, $M_{s}$, of the ferrimagnetic minerals is

$$
k_{h f}=k_{\text {para }}+k_{\text {dia }}+k_{\text {antiferro }}
$$

so that

$$
k_{f e r r i}=k_{l f}-k_{h f} .
$$

The results of high-field and low-field measurements are shown in Table 1. The high-field susceptibilities as a function of the lowfield values for the different lithological types are given in Figure 3A and Table 2. The discrimination is excellent. Light-colored lithologies have the lowest $k_{l f}$ and $k_{h f}$ and the dark-colored lithologies have high $k_{l f}$ and $k_{h f}$. The correlation between $k_{l f}$ and $k_{h f}$ is high $(\mathrm{R}=0.77$ for a logarithmic curve fit), which demonstrates that the magnitude of both $k_{l f}$ and $k_{h f}$ is strongly affected by the dilution of diamagnetic calcite $\left(k_{\text {dia }}\right)$.

The ferrimagnetic contribution $\left(k_{l f}-k_{h f}\right)$ in percent of $k_{l f}$ is plotted vs. $k_{l f}$ in Figure $3 \mathrm{~B}$. The ferrimagnetic contribution is high, between $33.5 \%$ and $85.8 \%$ (mean $=58.5 \%$ ). The mean values for the different lithological types $($ dark $=62.5 \%$, medium $=59.4 \%$, light $=52.8 \%)$ are clearly different and the correlation between $k_{f e r i}(\%)$ and $k_{l f}$ is significant $(\mathrm{R}=0.85$ for a logarithmic fit; Fig. 3B).

\section{Anhysteretic Remanent Magnetization}

ARM magnitude depends slightly on the calcium carbonate concentration (Table 2). Mean values are $0.17 \mathrm{~A} / \mathrm{m}$ for dark and intermediate layers and $0.14 \mathrm{~A} / \mathrm{m}$ for light layers. The highest ARM values are reached in dark layers, but the difference between the ARM of dark and light layers is not significant.

Acquisition of pARMs was performed on 12 samples (Fig. 4). Although the shape of the acquisition curves varies considerably, the maximum pARM that can be imparted is centered between 20 and 30 $\mathrm{mT}$ for all of the samples. This is typical of pseudosingle-domain (PSD) magnetite with a grain size between 2 and $3 \mu \mathrm{m}$ (Jackson et al., 1988, 1989). The shallow slopes of the curves at higher AFs represent sediments with a broader range of coercivities and, hence, grain sizes than sediments from which the steep curves were obtained.

\section{Hysteresis Characteristics}

Hysteresis parameters for each sample are listed in Table 1. Three examples of complete hysteresis loops after correction for the paramagnetic slope of the curve above the saturation magnetization are shown in Figure 5. The coercivity, $H_{c}$ (average $=16.9 \mathrm{mT}$ ), the coercivity of remanence, $H_{c r}$ (average $=42.8 \mathrm{mT}$ ), the saturation magnetization, $M_{s}$ (average $=0.0066 \mathrm{Am}^{2} / \mathrm{kg}$ ) and the saturation remanence, $M_{r s}$ (average $=0.00168 \mathrm{Am}^{2} / \mathrm{kg}$ ) are typical for PSD to fine PSD magnetite (e.g., Day et al., 1977; Dunlop, 1986; Borradaile et al., 1993; Roberts et al., 1995). Three loops that cover the entire spectrum of observed hysteresis properties are shown in Figure 5. Sample 154-929D-3H-1, $135 \mathrm{~cm}$, has the largest observed coercivity values, the highest $M_{r s} / M_{s}$ ratio, and the lowest $H_{c r} / H_{c}$ ratio (Fig. 5A). These parameters suggest the presence of fine-grained single domain (SD) magnetite or pyrrhotite. No other sample with similar properties was found. Sample 154-929D-2H-3, $80 \mathrm{~cm}$, has average hysteresis values and is typical of fine-grained PSD magnetite (Fig. 5B).The hysteresis properties of most of the samples are similar. The third example (Sample 154-929D-1H-3, $105 \mathrm{~cm}$ ) has low coercivities, a low $M_{r s} / M_{s}$ ratio, and a high $H_{c r} / H_{c}$ ratio, which is indicative of coarse-grained PSD magnetite. The paramagnetic slope has been subtracted from the loops, therefore the hysteresis parameters indicate the physical properties of the remanence carriers only. All of these intrinsic properties vary systematically among the different lithologies (Table 2), which is apparently a result of dilution by calcium carbonate. The ratios between these measurements $\left(H_{c r} / H_{c}\right.$ and $\left.M_{r s} / M_{s}\right)$ are independent of concentration and, although there is a tendency toward higher $H_{c r} / H_{c}$ ratios in the darker layers, a striking correlation between the ratios and lithology does not exist (Fig. 6). The grain size dependence of $H_{c r} / H_{c}$ and $M_{r s} / M_{s}$ can be used to estimate the domain state of the magnetic carrier (Day et al., 1977; Dunlop, 1986). The boundaries in Figure 6 delimit SD, PSD, and multidomain (MD) magnetite. These categories represent the increasing grain size of individual magnetite grains if the grains have similar internal dislocation densities, stress 


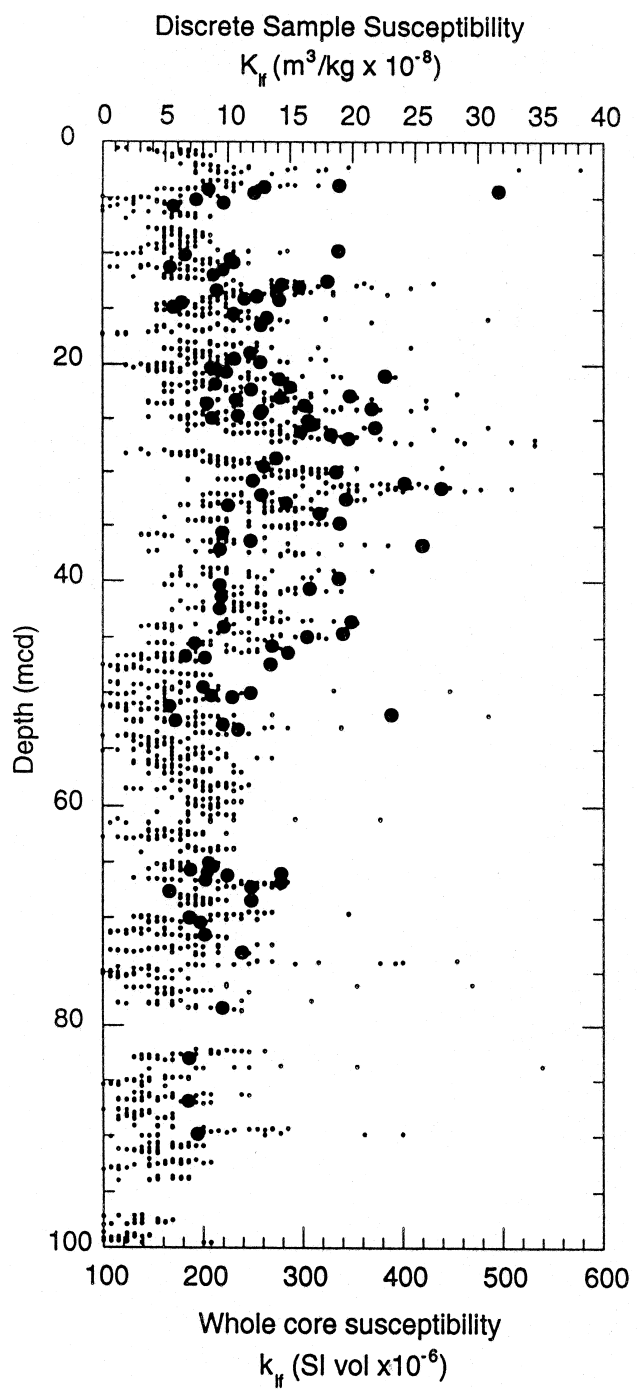

Figure 2. Whole-core (small dots) and discrete (large dots) low-field magnetic susceptibility variation vs. depth. Spliced section from Holes $929 \mathrm{C}$ and 929D. Depth scale is in meters composite depth (mcd). Whole-core susceptibilities are in volume SI units and discrete measurements are mass susceptibilities.

histories, stoichiometry and oxidation states. The boundaries are somewhat artificial, especially for the PSD-SD case in which grain shape can be influential (Butler and Banerjee, 1975). A plot of the hysteresis ratios shows that all of the samples (except one) plot in the PSD field. The diagonal trend from SD to MD fields indicates a range of grain sizes. Dark layers and light layers cannot be distinguished based on their magnetic grain size.

The presence of very fine grains and more specifically high $M_{r s} /$ $M_{s}$ values is rather unusual in sedimentary sequences. Very fine grains with this range of values would be observed if magnetite was of magnetotactic origin. However, the diagram in Figure 6 also shows that there is a large variability in grain sizes, which is difficult to reconcile with this hypothesis. Alternatively, the high $M_{r s} / M_{s}$ ratios could indicate the presence of iron sulfides like greigite. This hypothesis was initially envisaged as a cause of the remagnetization of the natural remanent magnetization (NRM) at all the sites drilled during Leg 154. The presence of this mineral is not compatible with the characteristics of the stepwise thermal demagnetization of the NRM performed on board (Curry, Shackleton, Richter, et al., 1995). The demagnetization curves display a single component of magnetization beyond $100^{\circ}-200^{\circ} \mathrm{C}$ with a single Curie temperature at $500^{\circ}-580^{\circ} \mathrm{C}$. The same experiments performed on very dark layers revealed different characteristics that point to pyrrhotite rather than greigite as the dominant iron sulfide. Thus, it seems likely that sulfides were preserved in very thin horizons when the geochemical conditions necessary for their preservation were met. This does not totally exclude that sulfides may be present in various but small quantities at any stratigraphic level. However, the amount of material is not large enough to cause significant variations in susceptibility. We will see in the next section that this view is confirmed by the thermomagnetic experiments.

The saturation magnetization $\left(M_{s}\right)$ and saturation remanence $\left(M_{r s}\right)$ are plotted vs. low-field susceptibility in Figure 7. $M_{s}$ (which is a measure of the concentration of ferrimagnets) and $M_{r s}$ behave linearly with susceptibility, which suggests that susceptibility is controlled by ferrimagnetic concentration rather than by a shift in grain size.

\section{Temperature Dependence of SIRM and Susceptibility}

Thermal demagnetization of a low-temperature (20 K) SIRM (Fig. 8) is used to estimate the amounts of ultrafine magnetic material. The loss in remanence between $20 \mathrm{~K}$ and room temperature reflects the unblocking of uniformly magnetized superparamagnetic (SP) grains (Néel, 1949; Cullity, 1972). The presence of the Verwey transition in all samples indicates that unoxidized grains are also present.

The strong low-temperature dependence of susceptibility (at 750 $\mathrm{Hz}$ ) between 20 and $100 \mathrm{~K}$ (Fig. 9) is caused by a superposition of the temperature dependence of paramagnetic material (Curie law) with the temperature-independent behavior of ferrimagnetic minerals (Richter and van der Pluijm, 1994). Although the low-temperature demagnetization data (Fig. 8) show the Verwey transition of magnetite at $118 \mathrm{~K}$, the susceptibility curve is unaffected by any phase transition (Fig. 9).

The presence of magnetite as the dominant mineral responsible for the susceptibility changes was confirmed by the results of the high temperature experiments performed on several samples in air. The two plots in Figure 9 show a unique and regular decrease of susceptibility between $400^{\circ}$ and $580{ }^{\circ} \mathrm{C}$, the Curie temperature of magnetite. Occasionally, more complex behavior was observed at low temperatures, which may reflect the presence of other mineralogical components, but in all cases the Curie temperature of magnetite was clearly identified. The absence of relationship between the magnitude of the susceptibility and the SIRM and the characteristics of the thermomagnetic curves is a strong indication that no other mineral besides magnetite plays a significant role in the susceptibility variations.

\section{DISCUSSION}

\section{Concentration of Magnetic Carrier Minerals}

Most of the magnetic parameters presented above are dependent on the magnetite concentration and the mineralogical composition of the sediment, especially the calcium carbonate concentration and the magnetite concentration. Some parameters (e.g., $M_{s}$ ) can be directly converted into the concentration of magnetite and others are indicators of the relative concentration of magnetite (e.g., $k$ and ARM). Magnetic grain size can be estimated from pARM curves, ratios of the hysteresis parameters $\left(M_{r s} / M_{s,} H_{c r} / H_{c}\right)$, and concentration-independent interparametric ratios such as SIRM/ARM, SIRM/ $k$, and $\mathrm{ARM} / k$. The SIRM/ARM ratio varies directly with magnetic particle size, whereas ARM/ $k$ and SIRM/ $k$ vary inversely with magnetic particle size (Robinson, 1986; Bloemendal et al., 1988; Maher, 1988).

Assuming that magnetite is the only mineral that contributes to room temperature hysteresis, the amount of magnetite can be calculated from the saturation magnetization extrapolated to zero field. The percentage of magnetite in individual samples is the $M_{s}$ of the 
Table 2. Mean values for rock magnetic parameters.

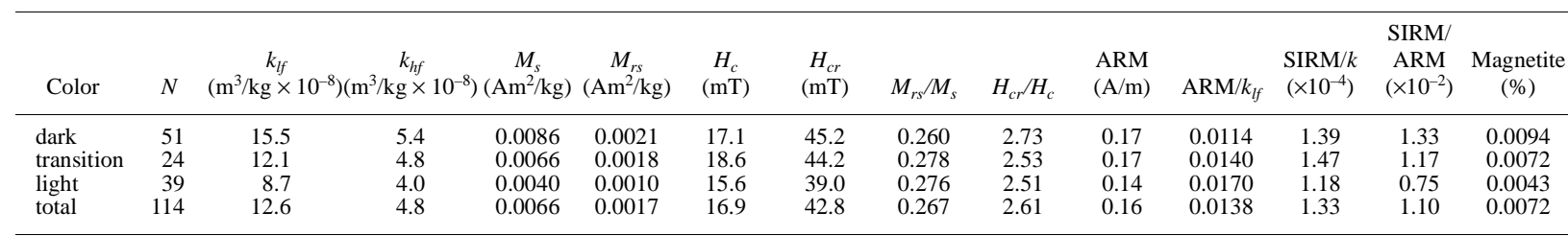
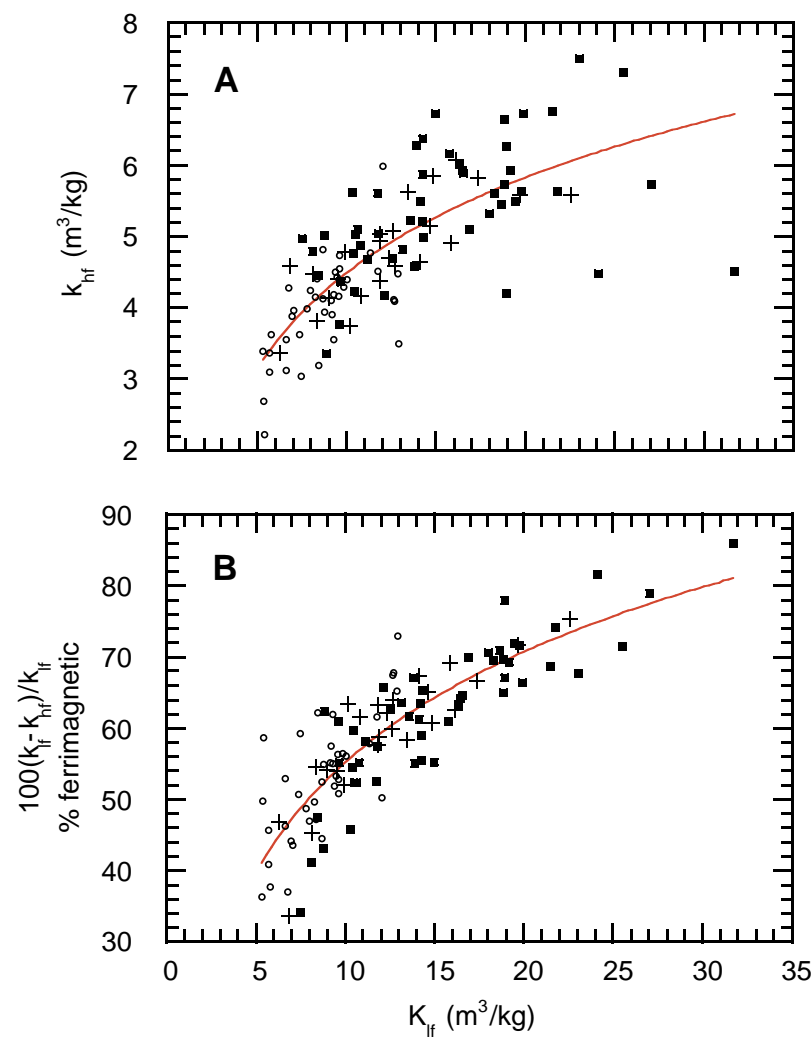

Figure 3. A. High-field vs. low-field susceptibility. B. Percent ferrimagnetic contribution to the low-field susceptibility vs. low-field susceptibility. Open circles $=$ light, calcium-carbonate rich layers; crosses = intermediate layers; black squares $=$ dark, calcium-carbonate poor layers .

sample divided by the $M_{s}$ of pure magnetite $\left(92 \mathrm{Am}^{2} / \mathrm{kg}\right)$, multiplied by 100 (Table 1). The magnetite concentration of the Site 929 samples determined by this method is low and varies from $21 \mathrm{ppm}$ to 257 ppm $($ mean $=72 \mathrm{ppm})$. On a small scale, the magnetite concentration is a function of lithology (Table 2), with highest concentrations in the dark layers and lowest concentrations in the light, calcium carbonaterich layers (Table 2; Fig. 10). The magnetite concentration decreases downhole, which is similar to the trend of the downhole distribution of magnetic susceptibilities (compare Fig. 2) and is also consistent with the slight downhole increase in calcium carbonate concentration (Curry, Shackleton, Richter, et al., 1995). Between 25 and 35 mcd, the magnetite concentration is above average, and below this depth drops constantly to its lowest values.

\section{Grain Size of the Magnetic Carriers}

The pARM measurements indicate a magnetic grain size of about 2-3 $\mu \mathrm{m}$ (Fig. 4). Hysteresis parameters (Fig. 6) indicate a magnetic grain size in the PSD field $(0.1-20 \mu \mathrm{m})$, which is consistent with the
pARM measurements. The low-temperature SIRM and susceptibility data also yield evidence for the presence of SP grains (Figs. 8, 9).

Variations in magnetic grain size and concentration were assessed in a bilogarithmic plot of susceptibility vs. SIRM (Fig. 11). Thompson and Oldfield (1986) calibrated this plot for magnetic grain size and concentration. However, they used a volume susceptibility instead of the mass susceptibility used in this study, requiring a qualitative interpretation of the diagram. In the diagram, dark layers have higher susceptibilities and saturation remanences, and hence, higher magnetite concentrations than the light layers. The magnetic grain size shows about the same scatter in the dark and the light layers.

Average values of the SIRM/ARM, SIRM/ $k$, and ARM/ $k$ ratios for dark and light layers (Table 2) indicate that lighter layers have a reduced particle size and darker layers have an increased particle size. The ratios SIRM/ARM and SIRM/ $k$ are plotted as a function of depth in Figure 12. Small-scale variations were eliminated by a 5point smoothing of the data. Both indicators of grain size correlate extremely well (correlation coefficient $\mathrm{R}=0.80$ ) and have basically identically shaped curves. The magnetic grain-size distribution is quite different from the magnetic concentration profile (compare Fig. 10), which means that periods of high magnetite input do not coincide with the deposition of coarser particle sizes. The particle size distribution shows three pronounced maxima at 20,27 , and $50 \mathrm{mcd}$, and one minimum at $67 \mathrm{mcd}$.

\section{Sources of Magnetic Susceptibility}

Because we found no evidence of antiferromagnetic grains, the previous equation for low-field susceptibility is reduced to

$$
k_{l f}=k_{\text {para }}+k_{\text {dia }}+k_{\text {ferri }} ;
$$

therefore, it is assumed that

$$
k_{l f}=\text { clay }+ \text { calcite }+ \text { magnetite } .
$$

Due to the high magnetic susceptibility of magnetite $\left(2 \times 10^{-4}-11\right.$ $\times 10^{-4} \mathrm{~m}^{3} / \mathrm{kg}$; e.g., Hunt et al., 1995), its contribution to the magnetic susceptibility signal is high despite its low concentration (58\% contribution for $72 \mathrm{ppm}$ concentration on average). In dark, carbonate-poor layers, the magnetite concentration is about twice as high as in the carbonate-rich, light-colored layers ( $94 \mathrm{ppm}$ vs. $43 \mathrm{ppm}$ ) and its contribution to magnetic susceptibility is about $10 \%$ higher (62\% vs. $52 \%)$. The concentration of the diamagnetic calcium carbonate varies between $3 \%$ and $50 \%$ in this part of the section. The magnetic susceptibility of calcium carbonate is negligible compared to the susceptibility of magnetite and clay and merely dilutes the magnetic susceptibility signal.

Magnetite is the major contributor to the magnetic susceptibility and, although it does not control it completely, the magnetite concentration and magnetic susceptibility correlate extremely well (Fig. 13). Linear regression $(\mathrm{R}=0.94)$ and interpolation to zero magnetite concentration indicates a background susceptibility of $4.53 \times 10^{-8} \mathrm{~m}^{3} / \mathrm{kg}$ (about $120 \times 10^{-6} \mathrm{vol} \mathrm{SI}$ ), consistent with expected values of phyllosilicates (Borradaile and Werner, 1994). Natural gamma-ray emission data that were measured during Leg 154 together with magnetic susceptibility measurements are shown in Figure 14. Both curves are 


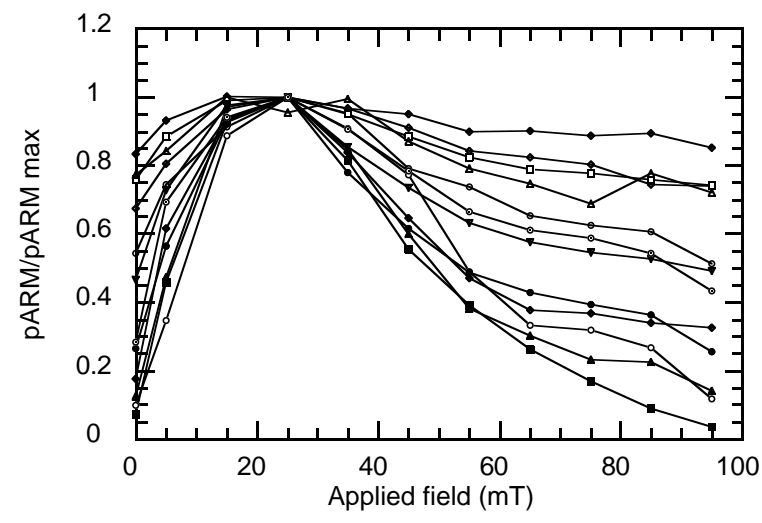

Figure 4. pARM curves of selected samples. The maximum PARM acquisition is at $20-30 \mathrm{mT}$, which indicates a PSD grain size in the order of $2-3 \times \mu \mathrm{m}$ (Jackson et al., 1988, 1989).
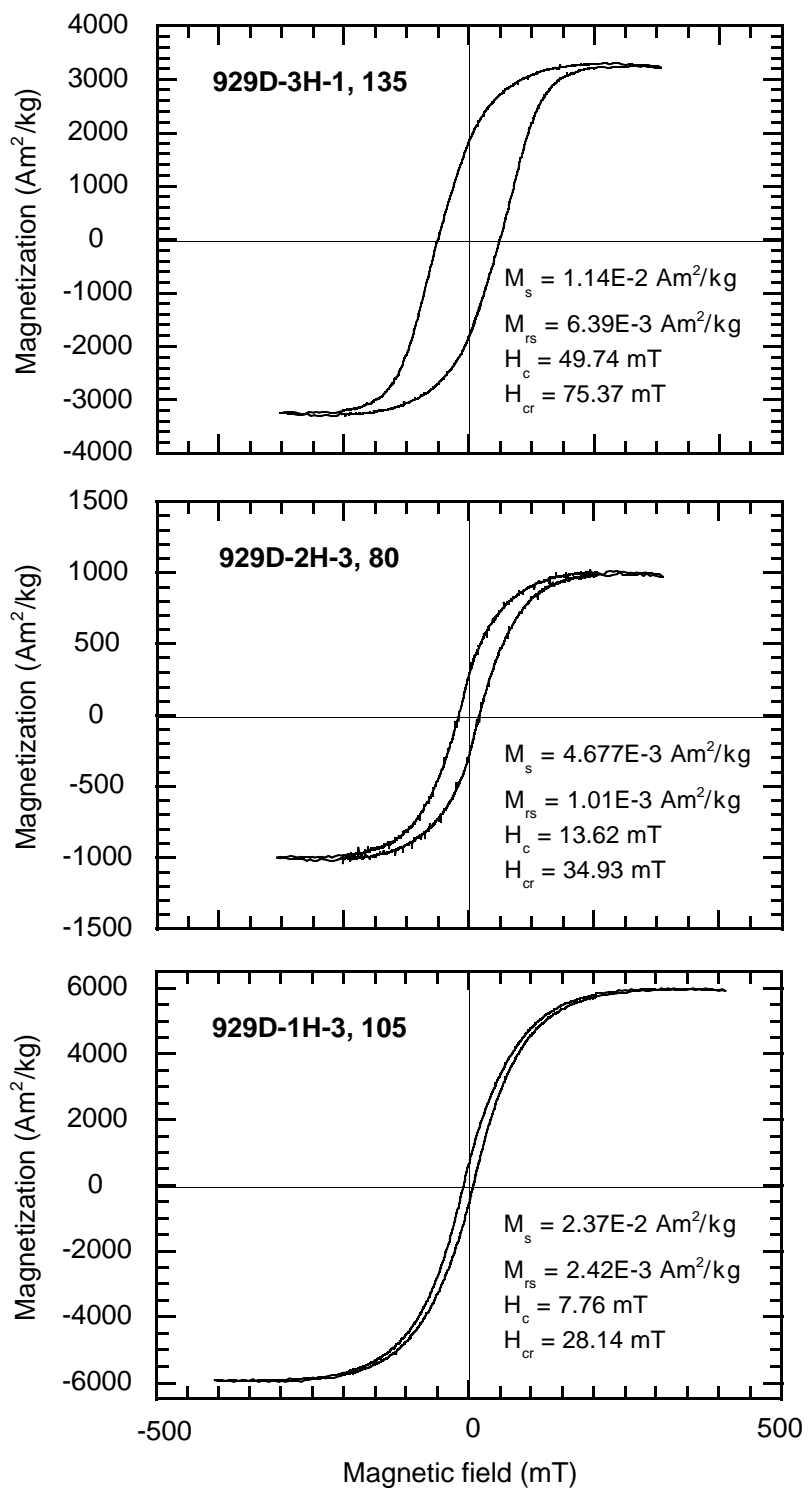

Figure 5. Three examples of hysteresis loops (corrected for paramagnetic slopes). Samples 154-929D-3H-1, $135 \mathrm{~cm}$ (top) and 154-929D-1H-3, $105 \mathrm{~cm}$ (bottom) have the most extreme properties, whereas Sample 154-929D-2H$3,80 \mathrm{~cm}$ (middle) is close to the average. smoothed (10-point) to eliminate small-scale variations. Natural gamma-ray emission measures the occurrence of clay minerals that contain radiogenic isotopes $(\mathrm{K}, \mathrm{Th}$, and $\mathrm{U})$. These minerals also tend to have high paramagnetic susceptibilities and are accompanied by magnetite or other magnetic minerals. The clay mineral concentration of the Ceara Rise sediments is dependent on terrigenous mineral input from the Amazon River. The terrigenous contribution increased during periods of low sea level and decreased during periods of high sea level. The good general correlation between the natural gamma and the susceptibility records on the one hand, and the susceptibility and magnetite concentration on the other hand, indicates that the magnetite concentration is directly controlled by fluctuations in sediment from the Amazon River.

\section{SUMMARY AND CONCLUSIONS}

We investigated the rock magnetic properties of samples from Site 929 on the northern flank of the Ceara Rise in order to obtain information about the relationship between climate-induced sedimentation variability and changes in the magnetic properties of the rocks. All magnetic properties, whether dependent on concentration, grain size, or composition, vary on small (half-meter) and larger scales reflecting fluctuations in the sedimentary input from the Amazon River. Our investigations demonstrate the following points.

1. Volume susceptibilities measured on the shipboard multisensor track correlate well with mass susceptibilities obtained from discrete samples. The discrete mass susceptibilities are of high accuracy and the excellent correlation with the shipboard data confirms the quality of the pass-through measurements.

2. Rock magnetic measurements and parameters correlate with small-scale cyclic variations in the sediment.

3. Low-temperature demagnetization data show the Verwey transition, which is indicative of magnetite.

4. We estimate from the saturation magnetization that the average magnetite concentration is $72 \mathrm{ppm}$. The magnetite concentration decreases downhole and is higher in darker, calcium carbonate-rich layers than in lighter calcium carbonate-poor layers. The linear correlation between magnetic susceptibility and magnetite concentration and extrapolation to zero percent magnetite determined a background susceptibility of $4.53 \times$ $10^{-8} \mathrm{~m}^{3} / \mathrm{kg}$.

5. The results of high-field and low-field measurements indicate that the magnetic susceptibility signal is dominated by magnetite. Magnetite contributions are $10 \%$ higher in dark layers than in light, carbonate-rich layers.

6. Hysteresis properties and partial anhysteretic magnetizations indicate that magnetite is of pseudosingle domain size. 


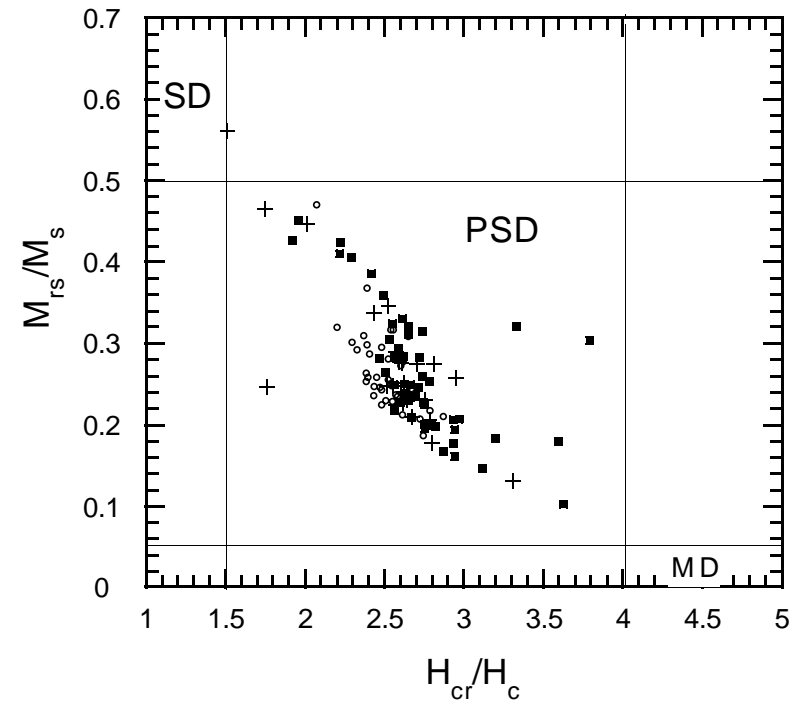

Figure 6. Plot of the hysteresis parameters in a diagram after Day et al. (1977). All samples (with one exception) fall into the pseudosingle domain (PSD) field. Symbols are the same as in Figure 3.

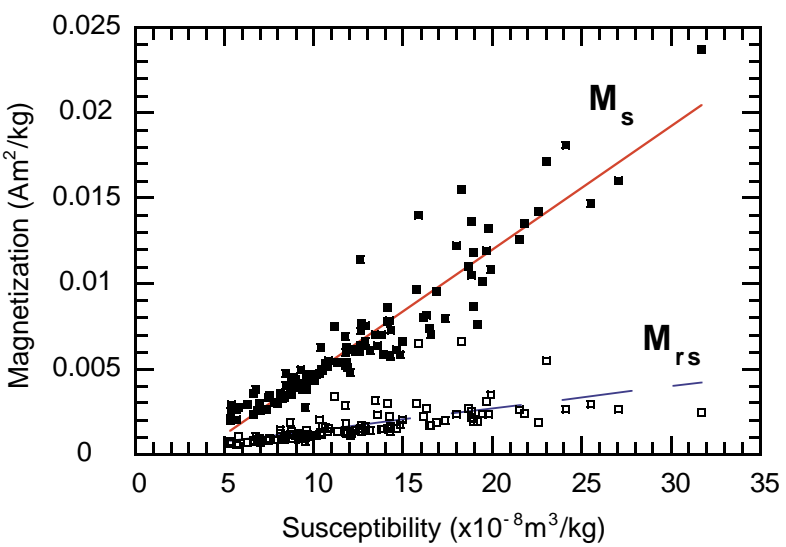

Figure 7. Saturation magnetization $\left(M_{s}\right)$ and saturation remanence $\left(M_{r s}\right)$ vs. low-field magnetic susceptibility. Both parameters show an excellent linear correlation $\left(M_{s}: \mathrm{R}=0.94 ; M_{r s}: \mathrm{R}=0.60\right)$.

7. Variations in magnetic grain size were investigated using concentration-independent SIRM/ARM and SIRM/ $k$ ratios. Both ratios display excellent agreement and exhibit small-scale and large-scale variations in grain-size distributions.

8. The clay and magnetite concentrations of the Ceara Rise sediments are controlled by terrigenous mineral input from the Amazon River, which increased during periods of low sea level and decreased during periods of high sea level.

\section{ACKNOWLEDGMENTS}

We thank the Institute for Rock Magnetism (IRM) for the use of its facilities. The IRM is funded by the Keck Foundation, the National Science Foundation, and the University of Minnesota. Thoughtful comments by Andrew Roberts, an anonymous reviewer, Laura Stokking, and Martin Ebel helped greatly to improve the manuscript.

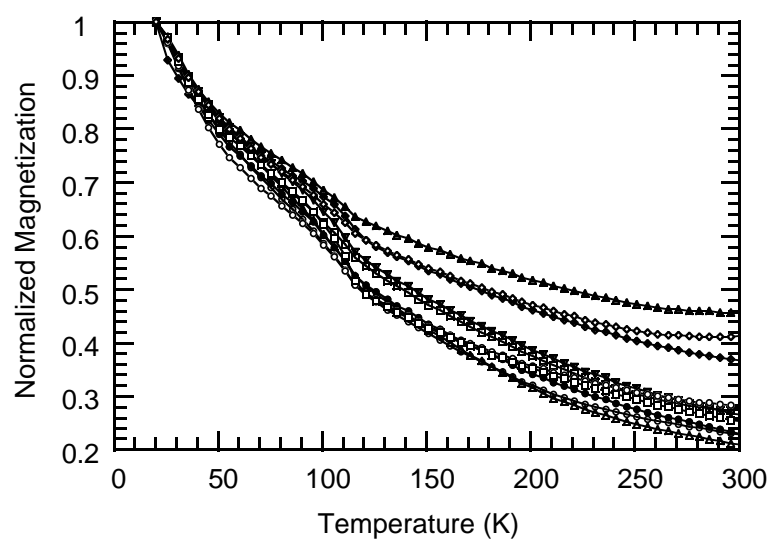

Figure 8. Low-temperature thermal demagnetization of a saturation isothermal remanent magnetization (SIRM) imparted at $20 \mathrm{~K}$. The strong remanence loss between 20 and $300 \mathrm{~K}$ indicates the presence of superparamagnetic (SP) particles. The step at $118 \mathrm{~K}$ is caused by the Verwey transition of magnetite.

\section{REFERENCES}

Bloemendal, J., and deMenocal, P., 1989. Evidence for a change in the periodicity of tropical climate cycles at $2.4 \mathrm{Myr}$ from whole-core magnetic susceptibility measurements. Nature, 342:897-900.

Bloemendal, J., King, J.W., Hall, F.R., and Doh, S.-J., 1992. Rock magnetism of late Neogene and Pleistocene deep-sea sediments: relationship to sediment source, diagenetic processes, and sediment lithology. J. Geophys. Res., 97:4361-4375.

Bloemendal, J., Lamb, B., and King, J., 1988. Paleoenvironmental implications of rock-magnetic properties of late Quaternary sediment cores from the eastern equatorial Atlantic. Paleoceanography, 3:61-87.

Borradaile, G.J., Chow, N., and Werner, T., 1993. Magnetic hysteresis of limestones: Facies control? Phys. Earth. Planet. Inter, 76:241-252.

Borradaile, G.J., and Werner, T., 1994. Magnetic anisotropy of some phyllosilicates. Tectonophysics, 235:223-248.

Butler, R.F., and Banerjee, S.K., 1975. Theoretical single-domain grain-size range in magnetite and titanomagnetite. J. Geophys. Res., 80:4049-4058.

Cullity, B.D., 1972. Introduction to Magnetic Materials: Reading, MA (Addison-Wesley).

Curry, W.B., Shackleton, N.J., Richter, C., et al., 1995. Proc. ODP, Init. Repts., 154: College Station, TX (Ocean Drilling Program).

Day, R., Fuller, M., and Schmidt, V.A., 1977. Hysteresis properties of titanomagnetites: grain-size and compositional dependence. Phys. Earth Planet. Inter., 13:260-267.

Dunlop, D.J., 1986. Hysteresis properties of magnetite and their dependence on particle size: a test of pseudo-single-domain remanence models. $J$. Geophys. Res., 91:9569-9584.

Hagelberg, T., Shackleton, N., Pisias, N., and Shipboard Scientific Party, 1992. Development of composite depth sections for Sites 844 through 854. In Mayer, L., Pisias, N., Janecek, T., et al., Proc. ODP, Init. Repts., 138 (Pt. 1): College Station, TX (Ocean Drilling Program), 79-85.

Hovan, S.A., Rea, D.K., Pisias, N.G., and Shackleton, N.J., 1989. A direct link between the China loess and marine $\delta^{18} \mathrm{O}$ records: aeolian flux to the North Pacific. Nature, 340:296-298.

Hunt, C.P., Banerjee, S.K., Han, J., Solheid, P.A., Oches, E., Sun, W., and Liu, T., 1995. Rock-magnetic proxies of climate change in the loesspalaeosol sequences of the western Loess Plateau of China. Geophys. J. Int., 123:232-244.

Jackson, M., Gruber, W., Marvin J., and Banerjee, S.K., 1988. Partial anhysteretic remanence and its anisotropy: applications and grainsize-dependence. Geophys. Res. Lett., 15:440-443.

Jackson, M., Sprowl, D., and Elwood, B.B., 1989. Anisotropies of partial and anhysteretic remanence and susceptibility in compacted black shales: grainsize- and composition-dependent magnetic fabric. Geophys. Res. Lett., 16:1063-1066. 
Kent, D.V., 1982. Apparent correlation of paleomagnetic intensity and climatic records in deep-sea sediments. Nature, 299:538-539.

Kukla, G., and An, Z., 1989. Loess stratigraphy in central China. Palaeogeogr., Palaeoclimatol., Palaeoecol., 72:203-225.

Kukla, G., Heller, F., Liu, X.M., Xu, T.C., Liu, T.S., and An, Z.S., 1988. Pleistocene climates in China dated by magnetic susceptibility. Geology, $16: 811-814$.

Maher, B.A., 1988. Magnetic properties of some synthetic sub-micron magnetites. Geophys. J. R. Astron. Soc., 94:83-96.

Maher, B.A., and Thompson R., 1992. Paleoclimatic significance of the mineral magnetic record of the Chinese loess and paleosols. Quat. Res., 37:155-170.

Mead, G.A., Tauxe, L., and LaBrecque, J.L., 1986. Oligocene paleoceanography of the South Atlantic: paleoclimatic implications of sediment accumulation rates and magnetic susceptibility. Paleoceanography, 1:273284.

Mountain, G.S., and Curry, W.B., 1995. Cruise Ew9209: Site survey for Leg 154. In Curry, W.B., Shackleton, N.J., Richter, C., et al., Proc. ODP, Init. Repts., 154: College Station, TX (Ocean Drilling Program), 39-52.

Néel, L., 1949. Théorie du trânnage magnétique des ferromagnétiques en grains fins avec applications aux terres cuites. Ann. Geophys., 5:99-136.
Richter, C., and van der Pluijm, B.A., 1994. Separation of paramagnetic and ferrimagnetic susceptibilities using low temperature magnetic susceptibilities and comparison with high field methods. Phys. Earth Planet. Inter, 82:113-123.

Roberts, A.P., Cui, Y.L., and Verosub, K.L., 1995. Wasp-waisted hysteresis loops: mineral magnetic characteristics and discrimination of components in mixed magnetic systems. J. Geophys. Res., 100:17,909-17,924.

Robinson, S.G., 1986. The late Pleistocene paleoclimatic record of North Atlantic deep-sea sediments revealed by mineral-magnetic measurements. Phys. Earth Planet. Inter., 42:22-47.

Shipboard Scientific Party, 1995. Ceara Rise Sediments Document Ancient Climate Change. Eos, 76:41-45.

Thompson, R., and Oldfield, F., 1986. Environmental Magnetism: London (Allen and Unwin)

Verosub, K.L., and Roberts, A.P., 1995. Environmental magnetism: past, present, and future. J. Geophys. Res., 100:2175-2192.

Date of initial receipt: 4 December 1995

Date of acceptance: 26 August 1996

Ms 154SR-133
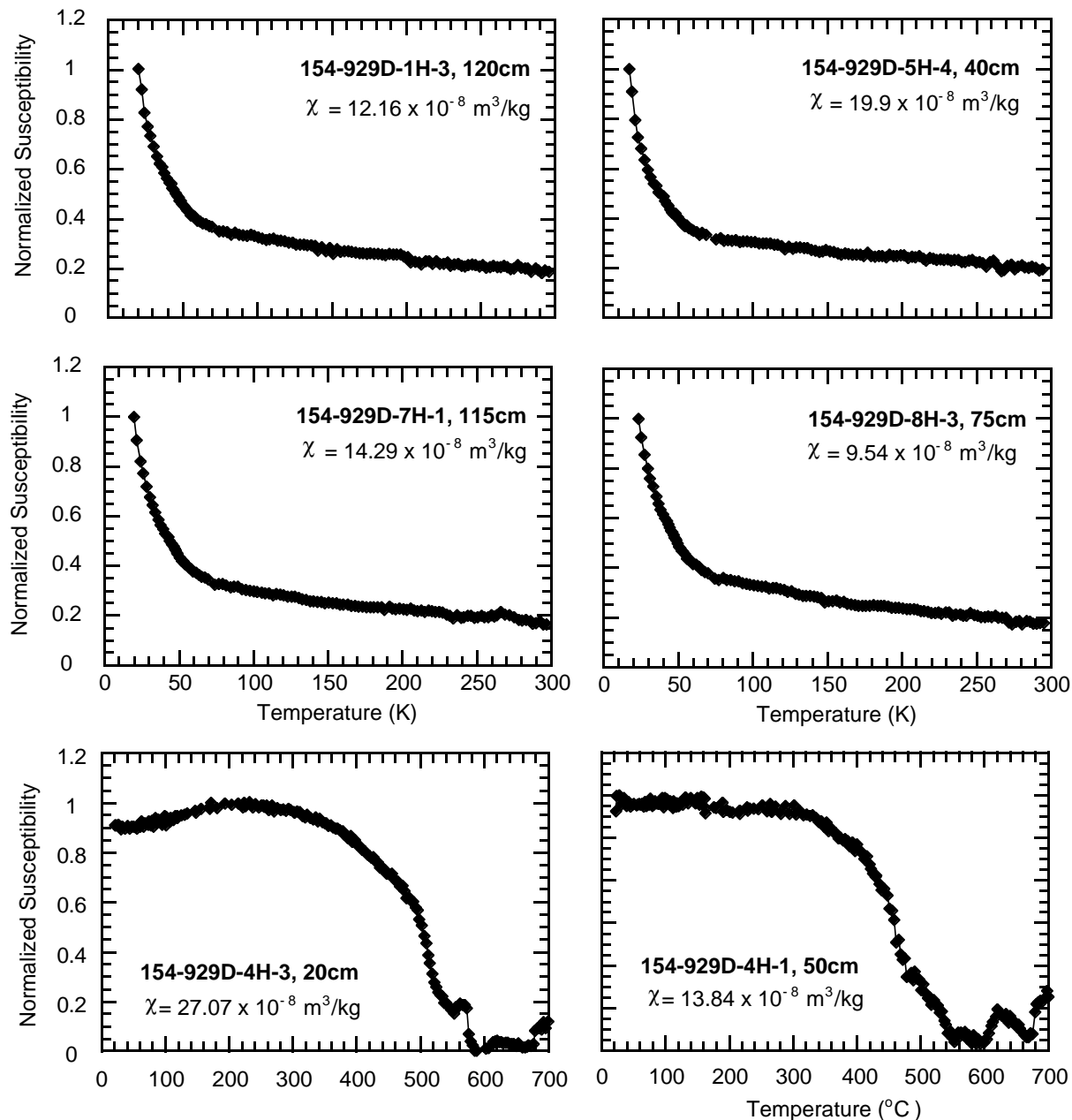

Figure 9. Low-temperature susceptibility curves between 20 and $300 \mathrm{~K}$. The rapid susceptibility loss between 20 and $60 \mathrm{~K}$ is probably caused by SP grains. The weaker susceptibility decay between 60 and $300 \mathrm{~K}$ is caused by the paramagnetic clay minerals. Note that the Verwey transition is not observed. 


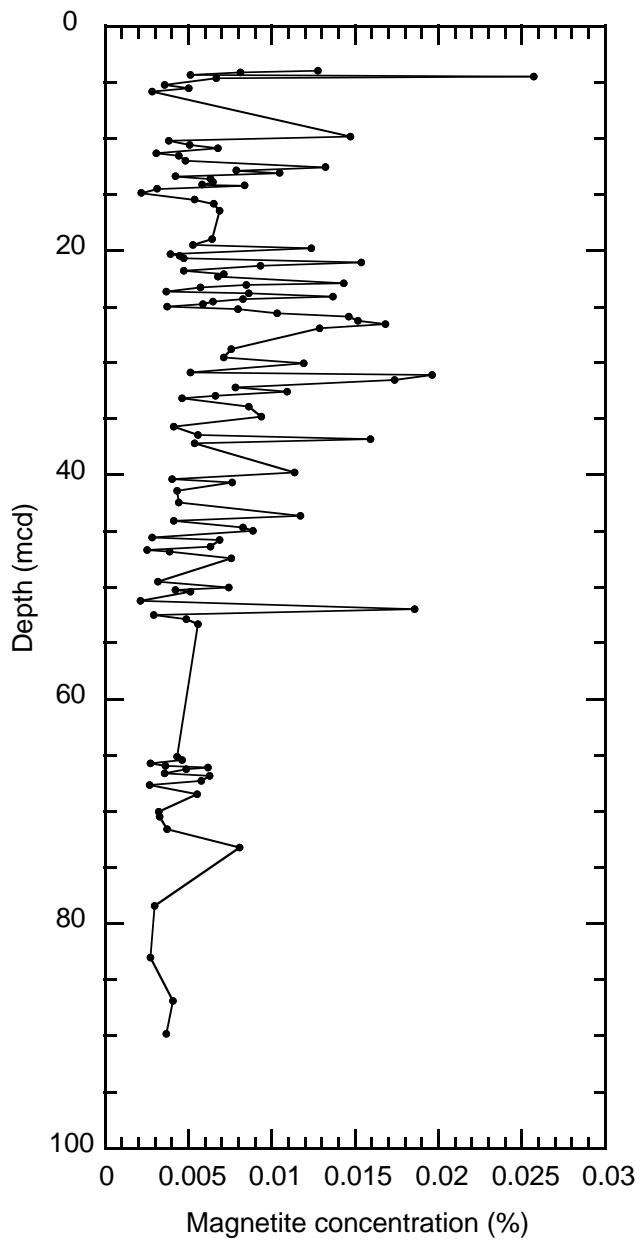

Figure 10. Concentration of magnetite as a function of depth. Values are calculated from the saturation magnetization under the assumption that magnetite is the only magnetic carrier mineral.

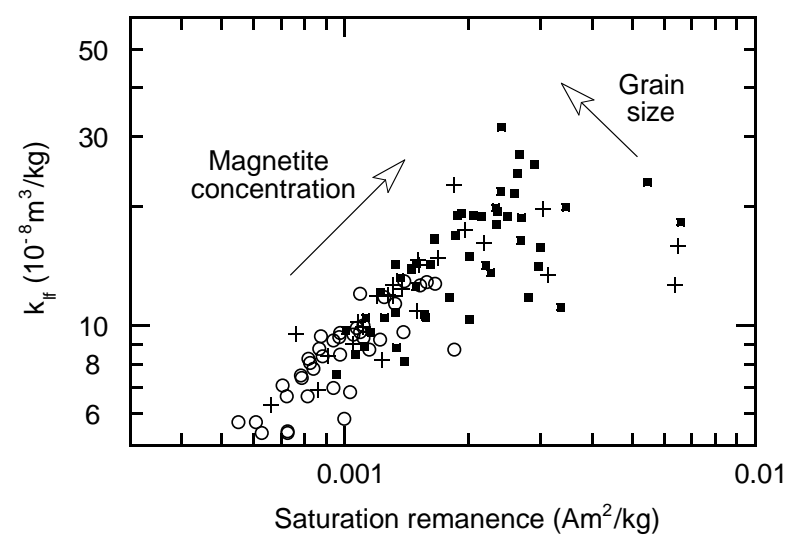

Figure 11. Bilogarithmic susceptibility vs. saturation remanence plot. Symbols are the same as in Figure 3. High magnetite concentrations plot toward the top right and low concentrations toward the bottom left of the diagram.

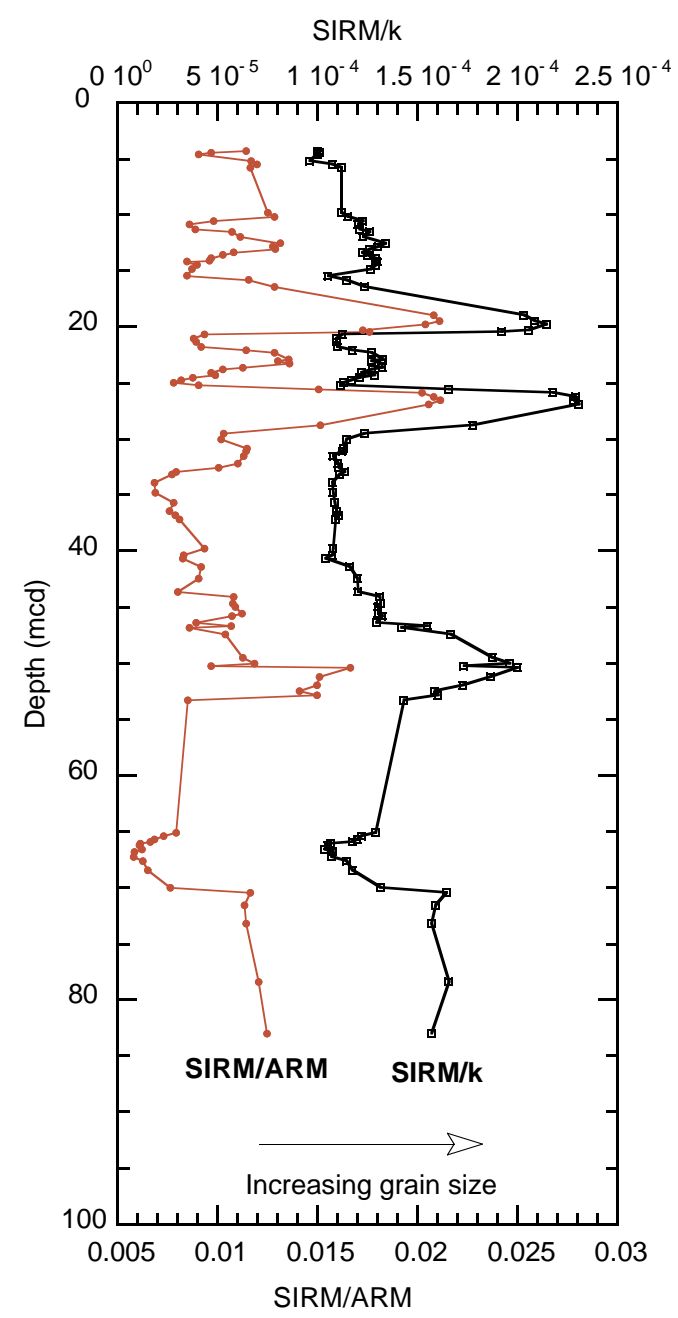

Figure 12. SIRM/ $k$ and SIRM/ARM vs. depth. Both ratios are concentrationindependent grain-size indicators. Data are smoothed (5-point).

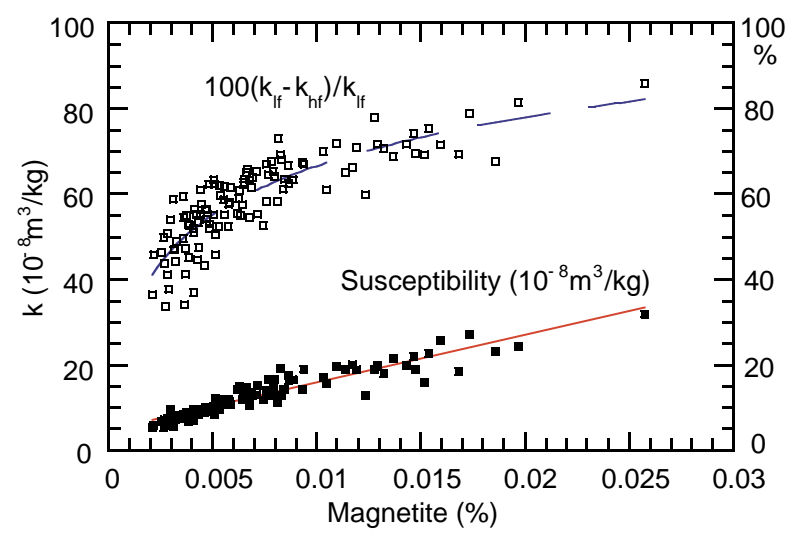

Figure 13. Magnetic susceptibility and percentage of ferrimagnetic contribution $\left(100\left(k_{l f}-k_{h f}\right) / k_{l f}\right.$ as a function of magnetite concentration. 


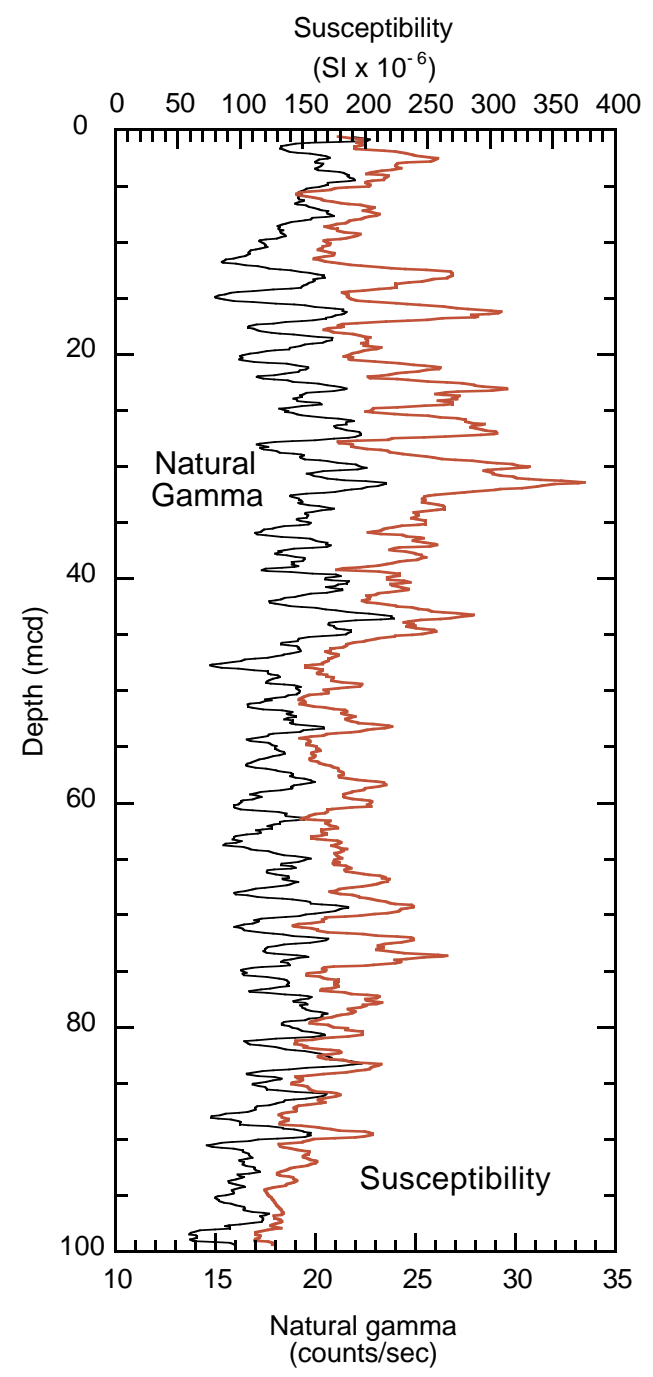

Figure 14. Spliced shipboard natural gamma-ray emission and magnetic susceptibility data (10-point smoothed) from Holes 929C and 929D on the mcd scale. 